\title{
PENGARUH SENAM DIABETES TERHADAP PENURUNAN KADAR GULA DARAH PADA PASIEN DIABETES MELITUS DI PUSKESMAS BAJENG KECAMATAN BAJENG KABUPATEN GOWA
}

\section{INFLUENCE OF DIABETES ON DEGREE OF BLOOD SUGAR RATE IN PATIENTS DIABETES MELITUS IN PUSKESMAS BAJENG DISTRICT BAJENG DISTRICT GOWA}

\author{
Lisya Hanifa ${ }^{1}$, Akulina Semana ${ }^{2}$, Nasrullah $^{3}$ \\ Poltekkes Kemenkes Makassar \\ Lisyahanifa2111@gmail.com
}

\begin{abstract}
ABSTRAK
Penyakit diabetes melitus merupakan penyakit yang disebabkan terganggunya hormon insulin sehingga terjadi peningkatan kadar gula dalam darah. Penyakit diabetes melitus ini salah satu penyakit berbahaya di dunia, penyakit ini tidak dapat disembuhkan tetapi hanya bisa di kontrol dengan cara menurunkan kadar gula dalam darah, penderita diabetes melitus selalu bertambah setiap tahunnya . Tujuan penelitian ini untuk mengetahui pengaruh senam diabetes terhadap penurunan kadar gula darah pada pasien diabetes melitus di Puskesmas Bajeng Kec.Bajeng Kab.Gowa. Penelitian ini menggunakan desain penelitian quasi eksperiment dengan rancangan penelitian one grup pretest - posttest design. Tehnik pengambilan sampel dilakukan dengan purposive sampling dengan jumlah sampel 30 orang. Penelitian ini menggunakan uji $T$ Berpasangan dengan tingkat kemaknaan $<\alpha=$ 0,05. Dari hasil uji statistik dapat disimpulkan bahwa ada pengaruh senam diabetes terhadap penurunan kadar gula darah pada pasien diabetes melitus dengan nilai $p=0,000$.
\end{abstract}

Kata Kunci : Senam Diabetes, Kadar Glukosa Darah

\section{ABSTRACT}

Diabetes mellitus disease is caused by disruption of the hormone insulin resulting in increased blood sugar levels. Diabetes mellitus disease is one of the most dangerous diseases in the world, this disease can not be cured but can only be controlled by lowering blood sugar levels, people with diabetes mellitus always increase every year. The purpose of this study to determine the effect of diabetes gymnastics on the decrease in blood sugar levels in patients with diabetes mellitus in Puskesmas Bajeng Kec.Bajeng Kab.Gowa. This research uses quasi experimental research design with one group pretest - posttest design. The sampling technique was done by purposive sampling with 30 samples. This research uses paired $T$ test with significance level $<\alpha=0,05$. From the results of statistical tests can be concluded that there is influence of diabetes gymnastics to decrease blood sugar levels in patients with diabetes mellitus with $p$ value $=0.000$.

Keywords: Gymnastics Diabetes, Blood Glucose Level

\section{PENDAHULUAN}

Penyakit diabetes melitus merupakan penyakit yang disebabkan terganggunya hormon insulin sehingga terjadi peningkatan kadar gula dalam darah. Penyakit diabetes melitus ini salah satu penyakit berbahaya di dunia, penyakit ini tidak dapat disembuhkan tetapi hanya bisa di kontrol dengan cara menurunkan kadar gula dalam darah, penderita diabetes melitus selalu bertambah setiap tahunnya (Hidayat, 2013).

Diabetes melitus adalah suatu penyakit dengan peningkatan glukosa darah di atas normal, dimana kadar glukosa darah diatur tingkatannya oleh hormon insulin yang di produksi oleh pankreas. Peningkatan jumlah penderita diabetes akhir-akhir ini sangat cepat, dan banyak diantaranya tidak menyadari betapa seriusnya penyakit tersebut, hal ini disebabkan karena beberapa penderita tidak merasakan timbulnya gejala-gejala diabetes.

Menurut World Health Organization (WHO), 422 juta orang berusia lebih dari 18 tahun menderita diabetes melitus pada tahun 2014. Jumlah penderita diabetes meningkat antara tahun 1980 sampai 2014. Peningkatannya empat kali lebih tinggi dari 108 juta menjadi 422 orang (2016).

International Diabetes Federation (IDF) memperkirakan di seluruh dunia terdapat sekitar 415 juta atau $8,8 \%$ orang dewasa menderita diabetes 
berusia 20-79 tahun, tren ini berlanjut maka di perkirakan 642 juta orang pada tahun 2040 (2015). Indonesia pada tahun 2013, penderita diabetes melitus mengalami peningkatan sebesar 2,1\% lebih tinggi di bandingkan tahun 2007 yaitu $1,1 \%$. Ada beberapa provinsi yang mengalami kenaikan prevelensi yang cukup berarti yaitu Maluku $0,5 \%$ menjadi $2,1 \%$, Sulawesi Selatan $0,8 \%$ menjadi $3,4 \%$ dan Nusa Tenggara Timur 1,2\% menjadi 3,3\% dan dua provinsi yaitu Papua dan NTB mengalami penurunan (RISKESDES, 2013).

Sulawesi Selatan tahun 2013 yang di diagnosis oleh dokter sebesar $3,4 \%$. Penderita diabetes melitus yang di diagnosis tertinggi terdapat di kabupaten Pinrang yaitu sebesar 2,8\%, kota Makassar 2,5\%, kabupaten Toraja Utara 2,3\% dan kota Palopo 2,1\% (DEPKES, 2015).

Prevalensi penyakit diabetes melitus melitus di kabupaten Gowa provinsi Sulawesi Selatan adalah 3,2\% (RISKESDAS, 2013).

Meningkatnya jumlah penderita diabetes ini dikarenakan kebiasaan gaya hidup yang tidak sehat misalnya banyak mengkomsumsi makanan berlemak, sehingga menimbulkan kegemukan dan berkurangnya aktifitas fisik seperti olahraga yang membuat metabolisme dalam tubuh yang tidak sempurna sehingga tidak terkontrolnya kadar gula darah. Penyakit diabetes melitus dapat di cegah jika kita mengetahui dasar-dasar penyakit dengan baik dan mewaspadai perubahan gaya hidup kita (Bagus, 2013). Salah satu pilar pengelolaan DM adalah latihan jasmani. Latihan jasmani merupakan langkah awal dalam mencegah, mengontrol dan mengatasi diabetes. Latihan jasmani secara langsung dapat menyebabkan terjadinya peningkatan pemakaian glukosa oleh otot yang aktif dan lebih banyak jala-jala kapiler terbuka sehingga lebih banyak tersedia reseptor insulin dan reseptor insulin menjadi lebih aktif yang akan berpengaruh pada penurunan kadar glukosa darah pada pasien diabetes (ILYAS, 2013).

Latihan jasmani merupakan aktivitas yang dapat menurunkan kadar glukosa darah salah satunya adalah senam diabetes. Senam diabetes adalah senam yang di rancang menurut usia dan status fisik dan merupakan bagian dari pengobatan diabetes melitus. Pada waktu latihan jasmani otototot tubuh, sistem jantung dan sirkulasi darah serta pernafasan di aktifkan, sehingga metabolisme tubuh dapat menyeimbangkan cairan elektrolit serta asam basa harus menyesuaikan diri agar otot-otot akan menggunakan asam lemak bebas dan glukosa sebagai sumber tenaga atau energi. Bila latihan jasmani di mulai glukosa yang berasal dari glikogen di otot-otot pada waktu latihan jasmani mulai sebagai sumber tenaga dan glikogen otot berkurang, selanjutnya akan terjadinya pemakaian glukosa darah dan lemak bebas makin meningkat pula pemakaian glukosa yang berasal dari cadangan glikogen hepar. Apabila latihan di tingkatkan lagi, maka sumber tenaga terutama berasal dari asam lemak bebas dan lipolisis jaringan lemak (PERSADIA, 2010).

Berdasarkan data yang di dapatkan peneliti dari pendokumentasian Puskesmas Bajeng 2 bulan terakhir, data yang diperoleh berjumlah 160 penderita diabetes melitus. Sampel dalam penelitian ini berjumlah 30 orang yang di jadikan sebagai responden dalam penelitian yang sesuai dengan kriteria inklusi dan eksklusi.

Untuk mengatasi hal tersebut kami perlu penanganan gula darah terkontrol dan penanganan Diabetes melitus dengan latihan fisik sehingga tidak terjadi komplikasi. Berdasarkan uraian diatas, penulis tertarik untuk melakukan penelitian tentang "pengaruh senam diabetes terhadap penurunan kadar gula darah pada penderita diabetes melitus di wilayah kerja puskesmas Bajeng "

\section{METODE}

Penelitian ini merupakan jenis penelitian kuantitatif dengan menggunakan metode penelitian quasi eksperiment yang bertujuan untuk menjelaskan atau mengklarifikasi terjadinya sebuah hubungan menjelaskan hubungan sebab sehingga dapat dijadikan sebagai dasar memprediksi sebuah fenomena (Hidayat, 2017). Penelitian ini menggunakan rancangan one gruoup pretest-posttes design tanpa kelompok kontrol. Dimana sebelum melakukan senam diabetes terlebih dahulu dilakukan pemeriksaan gula darah pretest senam diabetes pada responden, setelah itu diberikan perlakuan berupa senam diabetes. Terakhir dilakukan kembali pemeriksaan kadar gula darah post tes senam diabetes pada responden (Hidayat, 2017).

\section{HASIL}

Penelitian ini di laksanakan di wilayah kerja puskesmas Bajeng Kecamatan Bajeng Kabupaten Gowa pada tanggal 5 April - 5 Mei 2018 dengan jumlah sampel sebanyak 30 orang dengan menggunakan purposive sampling yang dilakukan sebanyak 4 kali dalam sebulan satu kali seminggu.

Penelitian ini termasuk penelitian kuantitatif dengan menggunakan quasi eksperiment dengan pre test dan post test design, dimana sebelum melakukan senam diabetes terlebih dahulu dilakukan pemeriksaan gula darah, setelah itu diberikan perlakuan berupa senam diabetes dan terakhir di lakukan kembali pemeriksaan kadar gula darah.

Penelitian ini melalui proses pengumpulan data yang di lakukan pada 5 Mei 2018 dengan menggunakan lembar observasi dan glukometer. 
Kemudian data diolah dengan program komputer dengan menggunakan uji $T$ Berpasangan dan selengkapnya akan disajikan dalam bentuk tabel distribusi frekuensi diikuti penjelasan dalam bentuk narasi.

Tabel 4.1

Distribusi Frekuensi Responden Berdasarkan Umur di Wilayah Kerja Puskesmas Bajeng Tahun 2018

\begin{tabular}{ccc}
\hline Kategori Umur & $\mathbf{F}$ & $\%$ \\
\hline $41-47$ tahun & 3 & 10,0 \\
\hline $47-53$ tahun & 1 & 3,3 \\
\hline $53-59$ tahun & 7 & 23,3 \\
\hline $59-65$ tahun & 9 & 30,0 \\
\hline $65-71$ tahun & 8 & 26,7 \\
\hline $71-77$ tahun & 1 & 3,3 \\
\hline $77-83$ tahun & 1 & 3,3 \\
\hline Total & $\mathbf{3 0}$ & $\mathbf{1 0 0}$ \\
\hline
\end{tabular}

Sumber : Data Primer 2018

Berdasarkan tabel 4.1 dapat diketahui bahwa untuk kategori umur pada penderita diabetes melitus di wilayah kerja puskesmas Bajeng terbanyak pada usia 59-65 tahun yakni 9 orang $(30,0 \%)$ dan untuk kategori umur yang paling sedikit yakni 47-53 $(3,3 \%), 71-77(3,3 \%)$, dan $77-83(3,3 \%)$.

Tabel 4.2

Distribusi Frekuensi Responden Berdasarkan Pekerjaan di Wilayah Kerja Puskesmas Bajeng Tahun 2018

\begin{tabular}{cll}
\hline Pekerjaan & F & $\%$ \\
\hline & 17 & 56,7 \\
\hline Pensiunan & 2 & 6,7 \\
\hline Petani & 1 & 3,3 \\
\hline PNS & 9 & 30,0 \\
\hline TNI & 1 & 3,3 \\
\hline Total & $\mathbf{3 0}$ & $\mathbf{1 0 0}$ \\
\hline \multicolumn{2}{c}{ Sumber : Data Primer 2018 }
\end{tabular}

Berdasarkan tabel 4 . 2 dapat di ketahui bahwa responden pada penderita diabetes melitus di wilayah kerja puskesmas Bajeng yang bekerja sebagai IRT sebanyak 17 orang $(56,7 \%)$, pensiunan 2 orang $(6,7 \%)$, sebagai Petani 1 orang $(3,3 \%)$, sebagai PNS sebanyak 9 orang $(30,0 \%)$ dan yang bekerja sebagai TNI hanya 1 orang $(3,3 \%)$.
Tabel 4.3

Distribusi Frekuensi Responden Berdasarkan Tekanan Darah di Wilayah Kerja Puskesmas Bajeng Tahun 2018

\begin{tabular}{lll}
\hline Tekanan Darah & F & $\%$ \\
\hline $110 / 70 \mathrm{mmHg}$ & 5 & 16,7 \\
\hline $120 / 80 \mathrm{mmHg}$ & 9 & 30,0 \\
\hline $130 / 60 \mathrm{mmHg}$ & 1 & 3,3 \\
\hline $130 / 80 \mathrm{mmHg}$ & 8 & 26,7 \\
\hline $140 / 80 \mathrm{mmHg}$ & 3 & 10,0 \\
\hline $150 / 80 \mathrm{mmHg}$ & 3 & 10,0 \\
\hline $170 / 90 \mathrm{mmHg}$ & 1 & 3,3 \\
\hline Total & $\mathbf{3 0}$ & $\mathbf{1 0 0}$ \\
\hline \multicolumn{2}{c}{ Sumber : Data Primer 2018}
\end{tabular}

Berdasarkan tabel 4 . 3 dapat di ketahui bahwa ada beberapa orang yang memiliki riwayat hipertensi yakni, 130/80 (26,7\%) sebanyak 8 orang, 140/80 $(10,0 \%)$ sebanyak 3 orang, $150 / 80(10,0 \%)$ sebanyak 3 orang dan $170 / 90(3,3 \%)$ hanya 1 orang.

\section{Tabel 4.4}

Distribusi Frekuensi Responden Berdasarkan kadar gula darah di Wilayah Kerja Puskesmas Bajeng Tahun 2018

\begin{tabular}{ccc}
\hline $\begin{array}{c}\text { Variabel Kadar Gula } \\
\text { Darah }\end{array}$ & Pre & Post \\
\hline Mean & 292,63 & 216,7 \\
\hline Minimum & 204 & 172 \\
\hline Maximum & 392 & 302 \\
\hline
\end{tabular}

Sumber : Data Primer 2018

Dari tabel 4.4 Menunjukkan bahwa nilai ratarata dari kadar gula darah sebelum melakukan senam adalah 292,63,dan nilai minimum adalah 204 ,maximum adalah 392. Kemudian nilai rata-rata dengan kadar gula darah pada paisen diabetes melitus setelah melakukan senam adalah 216,7 dengan nilai minimum 172 dan nilai maximum adalah 302.

Tabel 4.5

Distribusi Frekuensi Responden Berdasarkan uji normalitas di Wilayah Kerja Puskesmas Bajeng Tahun 2018

\begin{tabular}{ccc}
\hline \multirow{2}{*}{ Variabel } & \multicolumn{2}{c}{ Kadar Gula Darah } \\
\cline { 2 - 3 } & $\mathrm{n}$ & Sig \\
\hline Pre & 30 &, 182 \\
\hline post & 30 &, 068 \\
\hline
\end{tabular}

Sumber : Data Primer 2018 
Berdasarkan tabel 4.5 Test of Normality ,untuk kategori Pre diperoleh nilai $p=0,182>p=0,05$, sedangkan untuk kategori Post di peroleh nilai $p=$ $0,068>p=0,05$. Karena nilai kategori Pre $p=$ $0.182>0.05$, maka dapat disimpulkan bahwa data diatas berdistribusi normal. Yang selanjutnya dilakukan uji T Berpasangan

Tabel 4.6

Distribusi Frekuensi Responden Berdasarkan uji T Berpasangan di Wilayah Kerja Puskesmas Bajeng Tahun 2018

\begin{tabular}{lcc}
\hline & Varibel & Paired difference \\
\cline { 3 - 3 } & & Signifikasi (nilai p) \\
\hline Pair 1 & pre-post & 0,000
\end{tabular}

Sumber : Data Primer 2018

Berdasarkan tabel Paired Samples Test, diperoleh nilai $p=0.000<0.05$ sehingga data dapat disimpulkan bahwa ada pengaruh antara kadar gula darah dan senam.

\section{PEMBAHASAN}

Berdasarkan hasil penelitian di peroleh hasil uji $T$ berpasangan dengan nilai $p=0,000<0,005$ artinya ada pengaruh senam diabetes terhadap penurunan kadar gula darah pada pasien diabetes melitus di wilayah kerja puskesmas Bajeng kecamatan Bajeng kabupaten Gowa.

Menurut Sudirman dkk (2008) juga melakukan penelitian di RSU RA Kartini Jepara tentang pengaruh senam diabetes terhadap penurunan kadar gula darah pada penderita diabetes melitus, menggunakan metode penelitian quasi eksperimental dengan rancangan penelitian One Group Pre Test dan post test, dengan uji $T$ berpasangan kepada 67 responden di dapatkan nilai $(p=0,000)$, yang mana bahwa hasil dari penelitian ini menunjukkan bahwa adanya perubahan yang signifikan. Penelitian ini mendukung dari hasil penelitian yang di lakukan oleh peneliti Kartika Wahyu (2011) pada anggota PERSADIA Ciputat Jaya juga terkait pada efek senam diabetes melitus terhadap glukosa darah sewaktu pada penderita DM , menggunakan metode penelitian eksperimental dengan rancangan penelitian pre test dan post test dan menggunakan uji $T$ berpasangan yang mana kelompok perlakuan sebanyak 12 orang yang teratur melakukan senam diabetes melitus dan kelompok kontrol sebanyak 12 orang yang tidak pernah melakukan senam diabetes melitus, di dapatkan $(p=0,013)$ dengan rata-rata penurunan kadar glukosa darah sebesar $31,92 \mathrm{mg} / \mathrm{dl}$, sedangkan kelompok kontrol nilai $(p=0,023)$ dengan penurunan rata-rata $27 \mathrm{mg} / \mathrm{dl}$ dan penelitian yang dilakukan Kartika Wahyu mendukung hasil penelitian yang di lakukan oleh peneliti.

Hasil penelitian lain oleh penelitian yang di lakukan oleh Febriana (2010) di PERSADIA cabang Salatiga terkait dengan pengaruh senam diabetes melitus terhadap penurunan kadar glukosa darah pada penderita diabetes melitus di Surakarta, dengan menggunakan metode penelitian quasi Ekseperimen dengan rancangan penelitian One Group Pre Test dan Post Test Desaign dengan uji T berpasangan, yang mana jumlah responden sebanyak 242, didapatkan nilai $(p=0,000)$ yang artinya bahwa adanya perubahan yang signifikan setelah dilakukannya senam Diabetes Melitus.

Hal ini didukung oleh penelitian yang di lakukan Nanda dkk (2015) terdapat pengaruh senam diabetes terhadap penurunan kadar gula darah pada pasien diabetes melitus di Desa Botung kecamatan Kotanopan kabupaten Mandailing Natal tahun 2015, dengan penurunan rata-rata sebesar 49,182 mg/dl.

Menurut Yunir dalam Soegondo (2007) yang menyatakan kegiatan fisik dinamik yang melibatkan otot-otot utama akan menyebabkan permeabilitas meningkat pada otot-otot yang berkontraksi, sehingga saat latihan reseptor insulin akan lebih banyak dan lebih peka. Kepekaan reseptor insulin dapat berlangsung 12-24 jam setelah senam, yang menyebabkan glukosa darah dapat kembali normal.

Tujuan utama terapi diabetes adalah mencoba menormalkan aktivitas insulin dan kadar glukosa darah dalam upaya untuk mengurangi terjadinya komplikasi vaskuler serta neuropatik. Tujuan terapeutik pada setiap tipe diabetes adalah glukosa darah mencapai kadar glukosa darah normal (euglikemia) tanpa terjadinya hipoglikemia dan gangguan serius pada pola aktivitas pasien. Upaya penanganan pada pasien diabetes melitus sekaligus juga pencegahan terjadinya komplikasi adalah melakukan upaya pengendalian DM yang salah satu teraturnya pasien DM dalam melakukan aktifitas olahraga. Dengan berolahraga diharapkan memperbaiki sensivitas insulin sehingga dapat memperbaiki kadar gula dalam darah. Aktifitas fisik yang juga sering dianjurkan adalah senam diabetes melitus. Senam diabetes merupakan latihan fisik sebagai upaya mencegah dan mengontrol DM, dan merupakan salah satu pilar penatalaksanaan diabetes melitus disamping edukasi, terapi gizi, dan intervensi farmakologis. Manfaat aktifitas olahraga bagi penderita diabetes melitus antara lain meningkatkan penurunan kadar gula darah, mencegah kegemukan dengan cara membakar kalori tubuh sehingga glukosa darah bisa terpakai untuk energi. Dengan demikian kadar gulanya bisa turun. Senam diabetes dapat menyebabkan penurunan kadar glukosa darah, hal ini dikarenakan pada saat melakukan latihan fisik terjadi peningkatan 
pemakaian glukosa oleh otot. Selanjutnya terjadi peningkatan aliran darah yang menyebabkan lebih banyak jala-jala kapiler terbuka, sehingga reseptor insulin lebih banyak tersedia dan lebih aktif untuk menurunkan glukosa darah (wiwit Unairawati, 2011).

Senam diabetes dilakukan untuk menurunkan dan mengontrol kadar gula darah pada penderita diabetes melitus, setelah di berikan senam diabetes didapatkan hampir seluruhnya penderita diabetes melitus mengalami penurunan kadar gula darah, hal ini dikarenakan pada saat melakukan senam terjadi peningkatan pemakaian glukosa oleh otot, senam juga untuk membakar kalori tubuh sehingga glukosa darah bisa terpakai untuk energi. Dalam mengontrol dan menurunkan kadar gula darah dipengaruhi oleh beberapa faktor lainnya juga seperti berat badan, pendidikan dan faktor umur, dengan mengontrol pola makan/diet, meningkatkan pengetahuan tentang kesehatan, memberikan latihan fisik yaitu dengan senam diabetes yang dapat mengontrol dan menurunkan kadar gula darah sebagai modal pengobatan kedua. Namun tidak cukup hanya dengan latihan fisik saja tetapi juga harus di barengi dengan diet diabetes dengan memilih menu makanan yang tidak menyebabkan kadar gula darah meningkat, edukasi tentang diabetes dan juga minum obat, sebab olahraga hanya sebagai tambahan, alangkah baiknya jika hal tersebut juga di lakukan untuk mendapatkan hal yang lebih optimal.

$\mathrm{Hal}$ ini sejalan dengan penelitian yang dilakukan oleh Sunaryo 2013 tentang pengaruh senam diabetes terhadap penurunan kadar gula darah, dimana penderita yang mengikuti senam diabetes memiliki peluang menurunkan resiko diabetes sebanyak satu kali dibandingkan penderita DM yang tidak mengikuti senam. Keikutsertaan dalam senam diabetes didasari oleh sebagai alasan antara lain kesadaran pasien untuk meningkatkan kesehatan dan mengontrol gula darah, mengisi kesibukan dan anjuran dokter. Hal ini dipengaruhi oleh beberapa faktor, antara lain faktor pengetahuan atau persepsi terhadap penanganan dan perawatan diabetes, motivasi diri dan informasi. Dalam penelitian ini, ditemukan perubahan kadar gula darah pada pretest dan posttest setelah dilakukan senam diabetes melitus. Menurut pendapat peneliti, terjadi penurunan kadar gula darah kemungkinan dikarenakan keteraturan penderita dalam melakukan aktifitas senam diabetes serta kepatuhan diet dan minum obat oleh penderita diabetes melitus.

\section{KESIMPULAN}

Berdasarkan hasil penelitian di wilayah kerja puskesmas Bajeng dapat di tarik kesimpulan sebagai berikut :

Dari analisa data di lakukan dengan univariat dan bivariat menggunakan uji $\mathrm{T}$ berpasangan dengan taraf signifikan $p$ value $<0,00$ yang artinya ada pengaruh senam diabetes terhadap penurunan kadar gula darah pada pasien diabetes melitus di wilayah kerja puskesmas Bajeng kecamatan Bajeng Kabupaten Gowa

\section{SARAN}

1. Tempat penelitian

Disarankan bagi masyarakat khususnya bagi penderita diabetes melitus agar melakukan senam diabetes 3 kali seminggu dengan durasi 45 menit agar dapat membantu, mengontrol dan juga menurunkan kadar gula darah bagi diabetes, sehingga akan mengurangi angka kejadian diabetes.

2. Institusi Keperawatan

Dalam penelitian ini di dapatkan data bahwa ada pengaruh senam diabetes terhadap kadar gula darah pada pasien diabetes melitus, sehingga menjadi bahan masukan untuk mahasiswa dalam mengatasi maupun mencegah terjadinya kadar gula darah tinggi atau di atas normal pada diabetes untuk menyarankan senam diabetes.

3. Penelitian selanjutnya

Untuk penelitian selanjutnya agar melakukan penelitian yang tidak hanya melakukan senam diabetes terhadap penurunan kadar gula darahnya. Selain itu, untuk waktu penelitiannya juga bisa di perpanjang dari satu minggu,serta jumlah sampel yang lebih di perbanyak. Agar penelitian yang di hasilkan lebih akurat dan lebih baik lagi.

\section{DAFTAR PUSTAKA}

Daulay, M.N, Nasution Adriana, D, Nasution syah, S. (2015). Pengaruh senam diabetes terhadap penurunan kadar gula darah pada pasien Diabetes melitus di Desa Botung Kecamatan Kotanopan Kabupaten Mandailing Natal Tahun 2015. http ://ejurnal.stikesrshajimdn.ac.id. Diakses Tahun 2015.

Damayanti, S. (2015). Diabetes melitus dan penatalaksanaan keperawatan. Yogyakarta; Nuha Medika 
e-issn : 2622-0148, p-issn : 2087-0035

DEPKES(2015) http://www.depkes.go.id/resources/download/profil/PROFIL.KES PROVINSI 2014/27 Sulawesi Selatan 2014.pdf. diakses 29 Januari 2018

International Diabetes Federation (IDF) (2015)

http ://www.oedg.at/pdf/1606 IDF Atlas 2015 UK.pdf.Diakses 29 januari 2018

Kurnia, E, \& Prawesti, D. (2017). Senam kaki bagi pasien Diabetes melitus. Nganjuk; Adjie Media Nusantara

Maghfuri, A.(2017). Buku pintar perawatan luka Diabetes Melitus. Jakarta; Selemba Medika

PERKENI, (2015). Penatalaksaan Diabetes Melitus terpadu. Jakarta; Fakultas Kedokteran universitas indonesia

RISKESDAS(2013)

http://www.depkes.go.id/resources/download/general/Hasil\%20Riskesdas\%202013. Diakses 29 Januari 2018

Sumarni, T, \& Yudhoyono, D. T. (2013). Pengaruh senam kaki terhadap penurunan glukosa darah pada lansia dengan diabetes melitus di posyandu Lansia desa ledug kecamatan kembaran banyumas http ://www.academia.edu/download/44779598/16-44-1-PB.pdf. diakses 24 januari 2013

Tarwoto. (2012). Keperawatan medikal bedah gangguan sistem endokrin. Jakarta; TIM

World Health Organiztion (WHO).(2016)

http ://apps.who.int/iris/bitstream/10665/204874/1/WHO. NMH. NVI 16.3 eng.pdf. Diakses 29 januari 2018 